\title{
The Use of Photovoltaic Panels - The New Economic Challenge for the Future: Albanian Case
}

Eng. Luciana Toti

Phd Student, Department of Information Technology, Faculty of Information Technology, "Aleksander Moisiu" University Durrës, Albania, Europian University, Tirana

Mimoza Durresi

Doctor of Sciences, Department of Information Systems, Europian University, Tirana

\author{
Alma Stana \\ Doctor of Sciences, Department of Information Systems, Faculty of Information Technology, \\ "Aleksander Moisiu" University Durrës, Albania \\ Msc. Eng. Ferit Godole \\ Eng. Ajakida Eski \\ Phd Student, Department of Information Technology, \\ Faculty of Information Technology, "Aleksander Moisiu" University Durrës, Albania
}

Doi:10.5901/ajis.2015.v4n2p67

\section{Abstract}

The technology of photovoltaic (PV) systems is improving continuously in relation to their cost and performance, so their use is increased considerablyPV systems today are quite reliable in the different applications. The use of PV's as the electrical power source for a residence has reducing the need for electricity. Refrigerators, air conditioners, electric water heaters, electric ranges, electric dryers, and washing machines are all large users of electricity [7]. Alternative sources of energy are available to greatly reduce the use of electrical energy. In this paper, we are focused on the concept of installation solar photovoltaic (PV) system that generally requires engineering services for each individual application. There is relevant information regarded to PV systems stand-alone (off - grid) or grid connected (on - grid) ones. On the other hand there are a lot of guidelines on the subject of the design process of a PV system such as: the calculation of the electrical load, the size of the PV System, PV subsystems - inverters, controllers, wiring, mounting PV panels, batteries, types of photovoltaic cells [1]. The purpose of this paper is to show how PV panels can be used on the environments of a public institution in Albania conditions, in particular in one of the Albanian University (UET). The results of the study will be based on accurate calculation of installed solar panels and initial cost of their installation. Furthermore, in this paper it will also discuss the main advantages and disadvantages of implementing of this contemporary technology in our country.

Keywords: Photovoltaic moduke, designing a PV system, installation, energy consumption, calculation.

\section{Introduction}

The daily life issues like

- High prices of electric power supply

- $\quad$ Saving the Earth resources

- Environmental protection

Make the use of solar energy really imperative. Albania fortunately offers a great advantage in the applications of this technology, in view of the fact that the number of annual sunny days is very considerable.

This research will bring a lot of profits to the institutions and interested businesses that will use of solar power systems in the future. Even the European University of Tirana will certainly profit from this research after the installation of 
a similar system.

The main objective of the study is to make the economic analysis and to note the benefits obtained from the use of the solar energy for the European University of Tirana and for all Educational Institutions in Albania.

The significance of the study is related to the improvement of these aspects:

$\rightarrow$ The low cost for power supply in the Institution.

$\rightarrow$ Absence of technical failure as the ones randomly happening when power supplied by the national net.

$\rightarrow$ Social development.

At the end of the elaboration project, the Institution will have e new alternative source of electric energy.

\section{Theoretical Structure}

\subsection{What is a Solar Cell?}

A solar cell, in other terms known as "a photovoltaic cell", is a unit that transforms solar energy into electricity by means of photovoltaic effect [8].

The modern solar cells are based on the principles of semiconductor physics. They are simply joint $p-n$ photodiodes with a layer, which is very sensible to the light, placed in such a way to obtain a perpendicular position with the radiation from the sun (figure 1).

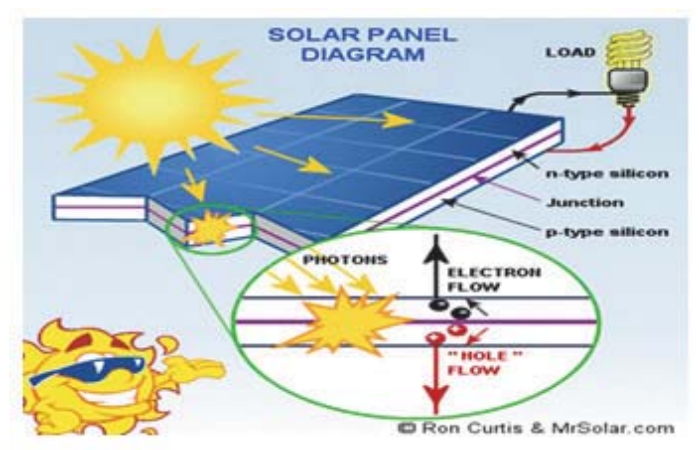

Figure 1: Solar panel diagram [25]

\subsection{Solar cell types}

There are three cell types that are classified by their manufacturing technology and the semiconductor type used (figure 2).

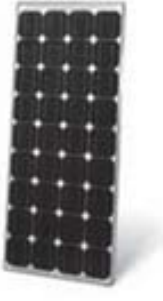

Single Crystalline Silicon
PV Module [26]

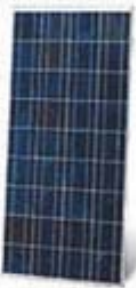

Polycrystalline Silicon PV Module [26]

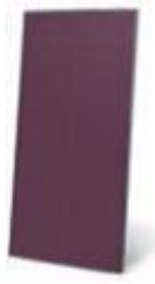

Amorphous Silicon PV Module [27]

Figure 2: Types of PV Module

- Crystalline Silicon PV Module: Two types of crystalline silicon (c-Si) are used to produce PV module; single crystalline silicon or known as mono-crystalline silicon and multi-crystalline silicon, also called polycrystalline 
silicon. The polycrystalline silicon PV module has lower conversion efficiency than single crystalline silicon PV module.

- Amorphous Silicon PV Module: Amorphous silicon (a-Si) PV module or thin-film silicon PV module absorbs light more effectively than crystalline silicon PV module, so it can be made thinner. It suits any applications, which do not require high efficiency and where keeping the low cost is important. The typical efficiency of amorphous silicon PV module is about $6 \%$.

- Hybrid Silicon PV Module: A combination of single crystalline silicon surrounded by thin layers of amorphous silicon provides excellent sensitivity to lower light levels or indirect light. The Hybrid silicon PV module has the highest level of conversion efficiency about $17 \%$.

Photovoltaic systems for the production of electricity in Western countries, mainly in the eurozone, thanks to supportive policies have widely been applied recently. Their installation consists of two main categories [30]:

* On-grid

* Off-grid

Technology of the installation of these two groups is the same; the only change is to the inverter, which gives the title to the system. For more detailed information we are explaining these two categories as follows [1].

\subsection{On-Grid Systems}

On-grid systems of the photovoltaic plants that produce electricity have the following components:

* Photovoltaic Modules

The solar panels which can be polycrystalline or mono-crystalline, are able to capture solar energy and convert it into direct electrical energy.

* Metallic structure (which may rotate or not in accordance with the rotation of the sun). Metallic structures are used for the installation and mechanical mounting of solar panels. This can be static or dynamic. Dynamic metallic structures have greater productivity from 35 to $45 \%$ more than the static ones.

+ Conductor of the direct current, because electricity produced by the panels is the direct electric current

* Meters of the electricity produced by the panels, distributed in the public network.

4 Meters of the public electricity network When the electricity generated by the panels is not enough for the needs of the customer, then the latter gets the electric power from the public grid.

* Electric control panel. When overhaul and other interventions are required, the system must be turned off. The control panel facility, consisted of electrical relays and fuses, is necessary.

* Inverter on-grid. To convert electricity into alternative electric current, the inverter is needed. And to make synchronization with the network, this inverter must be equipped with a synchronizing system, otherwise known as on - grid inverter.

* Conductor of the alternative current. To distribute alternative energy, current wires are needed. They are connected to the load distribution panel of the premise or customer.

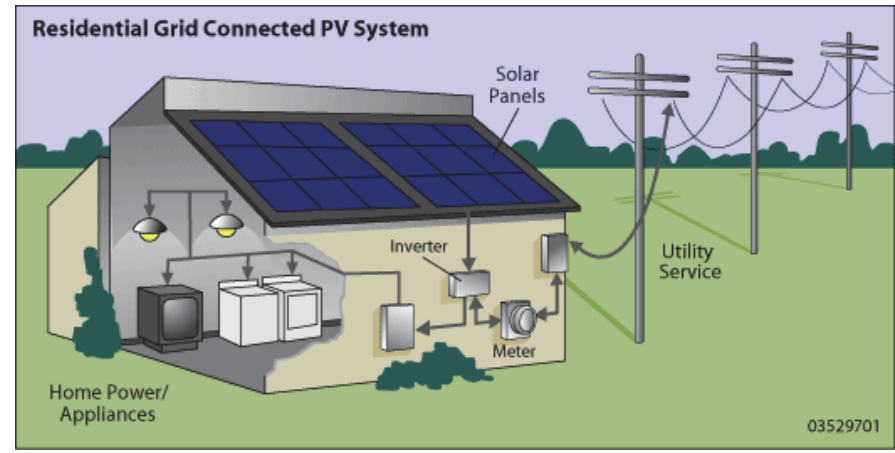

Figure 3: On-grid photovoltaic system [28]

These kinds of plants are widely used in urban and electrified rural zones. 


\subsection{Off-Grid Systems}

These systems requires batteries to store power for the times when the sun is not shining.

Off-grid systems plants that generate electricity by means of photovoltaic panels have the following components.

* Photovoltaic Modules

* Metallic structure (which may rotate or not in accordance with the rotation of the sun)

\pm Wires for the transmission of the direct current

* Meters of the electricity produced by the panels, distributed in the public network

* Meters of the public electricity network

* Electric control panel

\# Inverter off-grid

* Battery Charger

4 Batteries

* Wires for the transmission of the alternative current

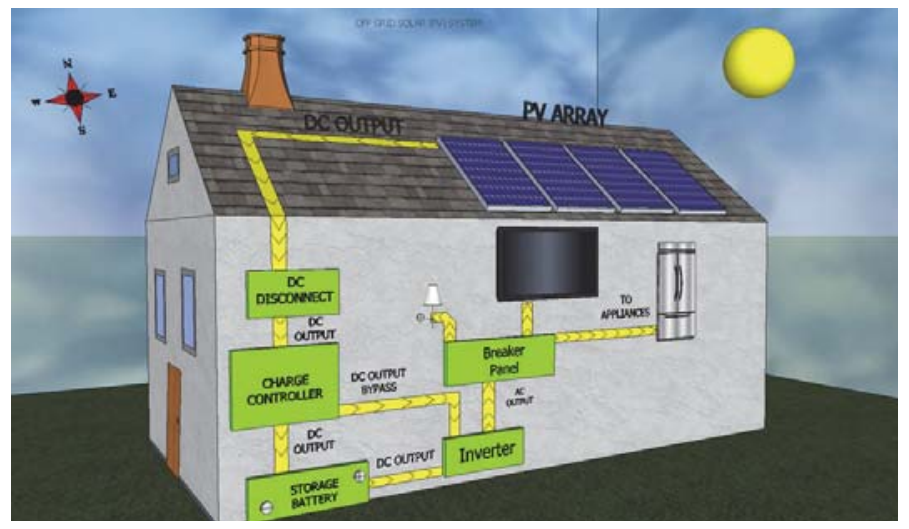

Figure 5: Schematic representation of an off-grid system [37]

Obviously, synchronization system is not needed for off-grid systems; therefore off-grid inverters have lower investment costs. But for these systems, the cost of the block of batteries is higher, which can raise the cost of the investment for the premise. The specific cost of the plant depends on the projects we will try to accomplish.

Off-grid systems are applied mainly in rural areas, where there is no public electrification.

\section{Research Design and Methods}

\subsection{Technical Calculations for On- Grid Photovoltaic System}

For technical calculations of the photovoltaic project the following should be known:

1. Power required for installation

2. Geographical position of the object

3. Physical surfaces that will be used for the installation of modules

Examine the above points.

\subsubsection{The power required for installation}

Albanian legislation does not include a special treatment for the exploitation of energy resources from solar panels. Therefore, power installation for solar photovoltaic panels, in order of not to create a disagreement with the distribution operator, or furthermore with the ERE (Energy Regulatory Agency), have the installed capacity calculated based on the consumption of the electricity for one calendar year, in a way that the balance of exchanged energy for a full year to be bigger or equal to zero. So, at the end of a calendar year the difference between the electricity meters of the public network with the electricity meter of PV plant, that distributes the electricity to the national system must be greater or 
equal to zero.

For the premises in question (EUT - European University of Tirana) we have access to the records of the electrical energy consumed annually. Data records that have been made available by the UET's administration, are presented in Table 1 and in graphical form in figure 8.

Table 1: Electricity consumption by UET for a calendar year

\begin{tabular}{|c|c|c|c|}
\hline Meter's number & \multicolumn{3}{|c|}{ H034510 } \\
\hline Date & Period & Value (Lek) & kWh \\
\hline $12 / 8 / 2012$ & $23 / 11 / 2012-25 / 12 / 2012$ & $377,495.20$ & $34,560.00$ \\
\hline $1 / 29 / 2013$ & $25 / 12 / 2012-23 / 01 / 2013$ & $178,314.40$ & $16,320.00$ \\
\hline $3 / 12 / 2013$ & $23 / 01 / 2013-22 / 02 / 2013$ & $280,525.60$ & $25,680.00$ \\
\hline $4 / 7 / 2013$ & $22 / 02 / 2013-21 / 03 / 2013$ & $254,317.60$ & $23,280.00$ \\
\hline $4 / 29 / 2013$ & $21 / 03 / 2013-18 / 04 / 2013$ & $330,320.80$ & $30,240.00$ \\
\hline $6 / 1 / 2013$ & $18 / 04 / 2013-20 / 05 / 2013$ & $266,111.20$ & $24,360.00$ \\
\hline $7 / 4 / 2013$ & $20 / 05 / 2013-19 / 06 / 2013$ & $279,215.20$ & $25,560.00$ \\
\hline $8 / 11 / 2013$ & $19 / 06 / 2013-23 / 07 / 2013$ & $284,456.80$ & $26,040.00$ \\
\hline $9 / 10 / 2013$ & $23 / 07 / 2013-31 / 08 / 2013$ & 340.00 & - \\
\hline $10 / 12 / 2013$ & $31 / 08 / 2013-23 / 09 / 2013$ & $277,904.80$ & $25,440.00$ \\
\hline $11 / 8 / 2013$ & $23 / 09 / 2013-23 / 10 / 2013$ & $334,252.00$ & $30,600.00$ \\
\hline $12 / 11 / 2013$ & $23 / 10 / 2013-22 / 11 / 2013$ & $266,111.20$ & $24,360.00$ \\
\hline & Sum & $3,129,364.80$ & $286,440.00$ \\
\hline
\end{tabular}

The graph of figure 6 gives a better view of the monthly energy consumption for the University.

As seen from the graph of figure 6 energy consumption for August is two low, due to the fact that during this period the university buildings are closed for the summer vacations. Another fact that is also worth mentioning is that the electricity consumption in January is lower than other months; this is related to the fact of the End of Year holidays. If we compare the energy consumption from February to March it seems that we have a declining tendency, with the arrival of spring and not using heating equipment. During April, we will assume that the consumption should be lower, but it is in contrary higher since the weather conditions could be changing, this can impose the use of heating or cooling equipment. From May to July there is a slight increase in electricity consumption, related to the fact that the use of equipment for cooling the building, which is a normal for such of the premise.

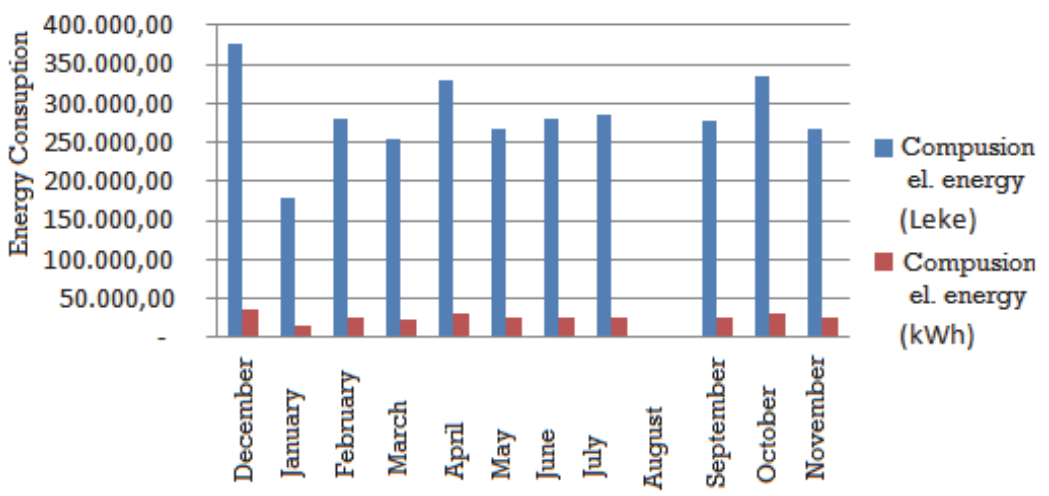

Figure 6. Monthly energy consumption for EUT

From Table 1 the total consumption for a calendar year is $E_{e l} .=286,440.00$ ( $k W h /$ year). Based on this we calculate the average monthly energy consumption:

$$
E_{\text {el/aver.monthly }}=\frac{\sum E_{e l}}{12}
$$

Where:

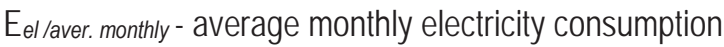


$\sum$ Eel . - Installed power

12 - months of a full calendar year

Applying formula 6.1 we get the average monthly consumption of electricity UET s.

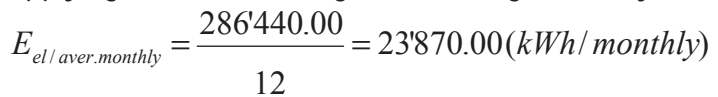

Based on average monthly and the annual energy consumption we calculate the peak power of the photovoltaic solar panels installation.

We know that the geographical position of Albanian is quite favorable for the application of technologies that utilize the solar energy. From the records of NANR there are over 280 sunny days in a year, with an average of over six hours daily of very hot sun. The experience shows that a photovoltaic plant installed in the Tirana works on average 8 to 10 hours a daily.

A very important element is the typology of the installation, static or dynamic; the lasted increases the production activity by 35-45\% compared to static installation. The use of the dynamic technology should require more the space, which for the project in question is limited. For this reason our calculations will be based on the static installation. Experience shows that a photovoltaic plant with static installation, the rate of electricity efficiency is $51 \%$ in a full calendar year.

$P_{I}=\frac{\sum E_{e l}}{365 \cdot 8 \cdot 0.51}$

where :

365 - days of a calendar year

$\mathrm{P}_{\mathrm{l}}$ - installed power

8 - Average working hours for a day

0,51 - Average efficiency factor of the photovoltaic plant for one calendar year.

Based on the formula 2, we determine the peak power of the installation of photovoltaic modules.

$P_{I}=\frac{286 ' 440.00}{365 \cdot 8 \cdot 0.51}=192(\mathrm{kWp})$

So, the power installation must be $192 \mathrm{kWp}$; we round up to the value $200 \mathrm{kWp}$

To reach this value we have selected poly-crystalline module with $250 \mathrm{Wp}$ power. The number of panels is:

$n=\frac{P_{I}}{P_{p}}$

where

$\mathrm{n}$ - the number of panels,

$\mathrm{P}_{\mathrm{I}}$-- installed power

$\mathrm{P}_{\mathrm{p}}$ - power of panel.

Based on the formula 3, we calculate the number of panels that will be installed.

$n=\frac{P_{I}}{P_{p}}=\frac{200}{0.25}=800$

Electricity produced from the solar panels depends on the angle of which panel face the sun, therefore their production varies in time during the day, from morning to evening. Based on international experience, photovoltaic solar panels installed on the static way in our country, produce energy by $60 \%$ to $75 \%$ of maximum installed capacity. Exploitation factor based on practical experience for a calendar year is 0,51

$P=P_{I} \cdot \lambda$

Where

$\lambda$ - exploitation factor in percentage, $51 \%$.

$P$ - effective power

Based on the formula 4, we determine the effective power productivity:

$P=P_{I} \cdot \lambda=200 \cdot 0.51=102(\mathrm{~kW})$ 


\subsubsection{The geographical location of the object}

The geographical position of the object consists in identifying geographical facility. We have taken into account the way that the object is exposed to sunlight, would be chosen the objects preferably oriented toward the south that have enough space (surfaces) available for installation of modules. To find out about our project we used the satellite surveillance facility.

Northern latitude: $41^{\circ} 19^{\prime} 17.73$ "N

East geographic length: $19^{\circ} 48^{\prime} 9.12$ "E

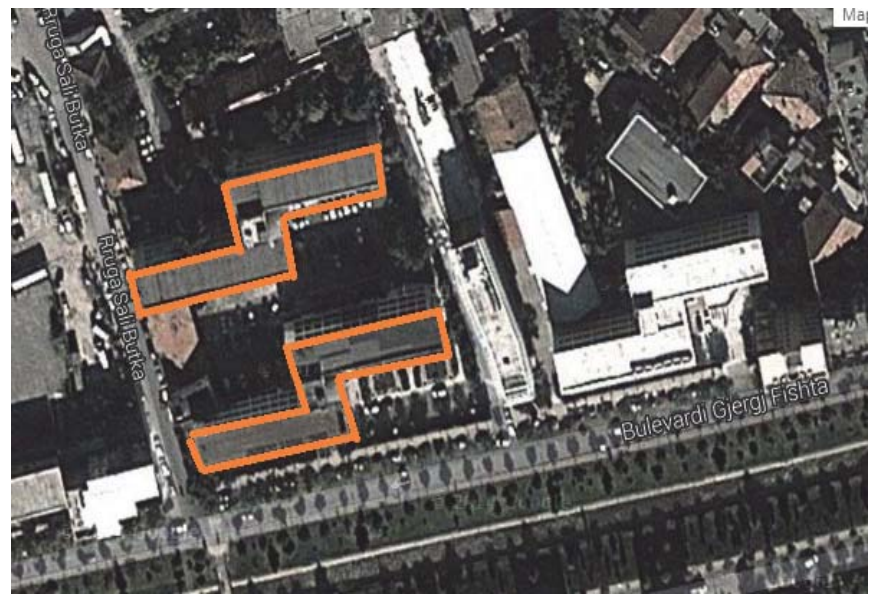

Figure 9. The geographical location of the object [36]

As you can see in Figure 9, the full object is positioned to South and the terrace is going to be used for the installation of the plant.

\subsubsection{Physical surfaces that will be used for the installation of modules}

Choosing the physical position that will be used for the installation of photovoltaic modules is a very important step, because this will directly affect the efficiency of the plant. If for producing $1 \mathrm{kWp}$ installed power will require $7 \mathrm{~m}^{2}$ up to 15 $\mathrm{m}^{2}$ surface area, then for the production of the $200 \mathrm{kWp}$ plant the surface area needed is going to be from $1400 \mathrm{~m}^{2}$ to $2400 \mathrm{~m}^{2}$.

The terrace 'surfaces of the object for a single building is approximately $1200 \mathrm{~m}^{2}$, both buildings about $2400 \mathrm{~m}^{2}$, which is enough for the installation of $200 \mathrm{KWp}$ power plant.

\section{Methods}

To achieve the objectives set out are using these methods:

a. Analytical is used to analyse the economic situation through the study of literature, scientific analysis, the relationship of variables and factors.

b. Comparative is used to compare the electricity consumption of a year from the network with those obtained from solar energy

c. Statistical is used to summarize the data and results in tables and graphical representation of the theoretical structure

As we mentioned above, the best part of the investment cost of the plant is required for the block batteries, especially when it is essential their self-sufficiency (autonomy). In addition, we refer the table 2 for the cost of entire plant. From our experience and the international ones, we conclude that costs of the electrical transmitters and the metal structure do not exceed $15 \%$ of the investment cost for the inverters and the modules. 
Table 2. Estimate the supply and installation of a hybrid system.

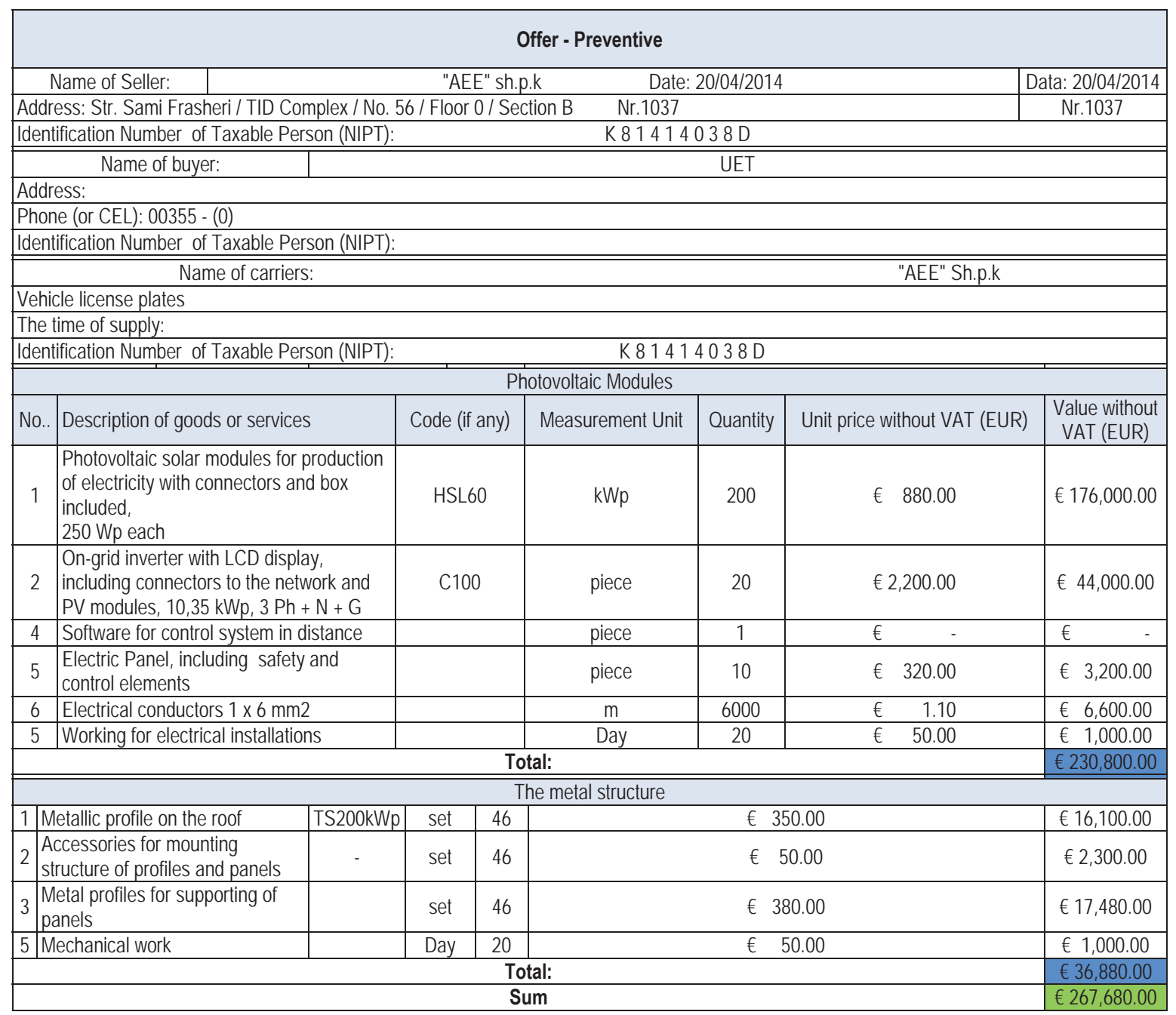

\section{Economic Analysis of On-Grid Photovoltaic System}

For understanding economic benefits in time, we follow calculating method, on the basis of available data. The produced energy by the PV plant for one day will be estimated:

$$
E_{\text {el. }}=P_{R} \cdot h_{d}
$$

Where:

Eeld - generated electrical energy for a day

$h_{d}$ - average hours of sunshine per day

Assuming that in Albania average hours of sunshine per day are 8-10, then the productivity of the plant will be :

$E_{\text {el. }}=200 \cdot 10 \cdot 0.51=816 \div 1020(\mathrm{kWh} /$ day $)$

As for the full calendar year the electrical energy generated by the plant will be :

$$
E_{\text {el. }}=E_{\text {el. }} \cdot 365
$$

Where:

Eel.y - generated electrical energy for a year 365 - days a year, in which the plant works an average of $51 \%$ of nominal power Then for a year electrical energy generated will be: $E_{\text {el. v }}=(816 \div 1020) \cdot 365=297^{\prime} 840.00 \div 372300.00(\mathrm{kWh} /$ year $)$ 
The electrical energy generated by the photovoltaic plant, will be evaluated by the purchased price offered by CEZ. This price is fixed by ERE and in our case is 10.0 Lek.

Then converted into monetary value of the electrical energy generated by the PV plant will be calculated according to the formula :

$$
C=E_{e l . v} \cdot 10
$$

Where:

$\mathrm{C}$ - the value, or the profit in money

10.0 Lek - the price of $1 \mathrm{kWh}$ of electrical energy, fixed by ERE

Applying the formula 7 and determine the money flow for the electrical energy generated by the PV plant.

$C=297 ' 840.00 \div 372 ' 300.00 \cdot 10.0=2^{\prime} 978{ }^{\prime} 400 \div 3 ' 723$ '000 (Leke / year )

Taxes are going to be applied on the above figures and these will be:

$$
C_{\text {taxes }}=\left(2^{\prime} 978^{\prime} 400 \div 3^{\prime} 723^{\prime} 000\right) \cdot 1.2=3^{\prime} 574^{\prime} 080.00 \div 4^{\prime} 467^{\prime} 600.00(\text { Leke/ year })
$$

Converted in Euros those figure will be:

$$
C_{E u}=\frac{C}{140}
$$

Where:

CEU - cost of electrical power converted into Euros.

140 is the approximate exchange rate Albanian Lek to one Euro.

By using the formula 8,we compute the financial income of the facility in Euros.

$$
C_{E u}=\frac{C}{140}=\frac{3^{\prime} 574^{\prime} 080.00 \div 4^{\prime} 467^{\prime} 600.00}{140}=25^{\prime} 529.00 \div 31^{\prime} 911.00 \text { (Euro) }
$$

The cost of investment $(\mathrm{Ci}$ ) of the plant consists of the following costs :

the cost of PV modules ( $\mathrm{Cm}$ )

the cost of Inverters ( Cin )

the cost of supporting screens ( Cs )

the cost of the installation ( Cst )

According to Table 2 the total cost of the installation for this plant that will produce $200 \mathrm{kWp}$, is $€ 267,680.00$. The costs includes all the works needed to be completed from the start of the project to the phase of the producing the electrical energy.

Deadline for the payback is calculated by knowing the initial outlay of the investment for this plant and the financial profits generated by the distribution of the electrical energy over a year.

$$
T=\frac{C_{T}}{C}
$$

Then we would have:

Where:

$T$ - the Payback time in years

By applying the formula 9 we find out the repayment figure in years.

$$
T=\frac{267^{\prime} 680.00}{25^{\prime} 529.00 \div 31^{\prime} 911.00}=10.5 \div 8.3 \text { (years) }
$$

Having in mind that of energy price is always increasing from year to year, we will assume that the time of payback for this plant is going to be lower.

Considering the benefits and the advantages of solar energy and that in the future the drop in per watt costs for solar energy will be a vital element in applying these technologies more in our country.

The advanced technologies will be used to reduce further the production cost of these installations, so in the future the choice of solar energy will be favored compared with other forms of production, if we will focus on the clean energy.

\section{Conclusions}

The application of photovoltaic systems in Albania, as well as worldwide, brings economic benefits. Their use, especially in Educational Institutions, brings social development, a healthier environment, absence of the technical problems and the saving of natural resources. 


\section{References}

\section{Books}

Photovoltaics Fundamentals, Technology And Practice, Konrad Mertens, Münster University of Applied Sciences, Germany, 2014 National Agency of Natural Resources, Solar and Renewable Energy in Albania - 2013

Photovoltaics System Design And Practice, Heinrich Ha"Berlin Berne University of Applied Sciences, Switzerland, 2012 Altin MARA:Ttraining program for energy auditors "Application of renewable resources buildings "

Università degli studi di Padova, Celle Fotovoltaiche di Graetzel - 2011

Manual for training course for photovoltaic panels

Solar Energy and Systems Engineering-PROCESSES 2009 (Malestrom)

Electronic Devices and Circuit Theory 9 Ed, Robert Boylestad, Louis nashelsky.

Meteotest. Valori della radiazione globale mensile in Kwh/m^2. s.I. : Photon, 2010.

Photovoltaic Design \& Installation For Dummies® 2010

How do Photovoltaic Work Lionel Vayssieres, On Solar Hydrogen \& Nanotechnology (2010)

Università degli studi di Padova, Studio della Dell'affidabilita e Risposta spettrale di Celle solari DSC -2011

G.N.Tiwari and Swapnil Dubey ,Fundamentals of Photovoltaic Modules and their Applications

Antonio Luque and Steven Hegedus, Handbook of Photovoltaic Science and Engineering(2 ed

Lewis Fraas, Solar Cells and Their Application

The Physics of Solar Cells

Photovoltaic Systems Engineering, second edition, Roger A. Messenger, Jerry Ventre, 2004

EPIA, Greenpeace \&. Solar Generation 6 - Executive summary. October - 2010.

EPIA, 2010. Global market outlook for photovoltaic's until 2014.

Solar Power in Building Design - The Engineer's Complete Design Resource

Solar Power for Your Home (2010)

Build Your Own Solar Panel

A guide to photovoltaic (pv) System design and installation, JUNE 2001

\section{Websites}

www.dgem.nl

www.greenenergy.review forcash.com

www. archiproducts.com

www. leonics.com

www.solar-system-china.com

http://photovoltaics.sustainablesources.com/

http://re.jrc.ec.europa.eu/pvgis/cmaps/eur.htm \# AL

http://www.meteotest.ch

http://www.retscreen.net

http://www.telegrafi.com/ekonomi

sq.wikipedia.org / wiki /

wikipedia.org/

https://maps.google.com

www.psi-solar.com

www.superior.com 